\title{
Immunity and Virulence in Bird-Parasite Interactions
}

\author{
Gabriele Sorci* and Stéphane Cornet*
}

BioGéoSciences, CNRS UMR 5561, Université de Bourgogne, 6 Boulevard Gabriel, 21000 Dijon, France

\begin{abstract}
The interaction between hosts and parasites is characterized by the evolution of reciproca adaptations aiming at reducing the cost of infection (from the host point of view) and to optimize host exploitation (from the parasite point of view). Within this co-evolutionary scenario, the immune system takes a central role. The immune system has evolved to fight off parasitic attacks. However, immune defences cannot be deployed without costs which set a limit to the protective effect of immunity. Moreover, immune defences impose strong selection pressures on the parasite and can favour the evolution of more virulent pathogen strains. In this article, we will discuss these different issues focusing on host-pathogen interactions involving birds and their parasites.
\end{abstract}

Keywords: Coevolution, immune response, immunopathology, infection, virulence.

\section{INTRODUCTION}

Interspecific interactions are now recognized as a major evolutionary force [1-3]. Virtually any organism has to face the threat imposed by competitors, predators and parasites. The selection pressures exerted by these interactions have favoured the evolution of specific adaptations that tend to limit the cost of competition, the risk of predation, and the cost of infection.

The immune system is, with no doubt, the principal weapon that hosts have evolved to fight off a parasitic attack [4]. Defence mechanisms against pathogens are already present in simple unicellular organisms and reach a high degree of complexity in vertebrates. The vertebrate immune response is characterized by a series of effectors that act in a synergistic and well-orchestrated way. Upon encounter with an invading parasite, a first line of defence is activated within minutes/hours. This innate, inflammatory, response provides an effective shield for most infectious threats. However, when the infection persists, a second line of defence is activated. The acquired immune response relies on effectors that require a longer time to be deployed, yet offer two major advantages: specificity and memory. Therefore, in a schematic way, we can say that the innate response provides a rapid but non specific protection, whereas the acquired response is slower but specifically targets the pathogen structures and provides a long lasting protection.

In spite of the complexity of the vertebrate immune system, pathogens remain a pervasive threat for their hosts. Obviously, the reason for this is that pathogens also respond to the threat imposed by the immune system by adopting a series of strategies that aim at escaping/reducing the effectiveness of the immune response [5]. This can lead to a coevolu-

*Address correspondence to these authors at the BioGéoSciences, CNRS UMR 5561, Université de Bourgogne, 6 Boulevard Gabriel, 21000 Dijon, France; E-mails: gabriele.sorci@u-bourgogne.fr and stephane.cornet@u-bourgogne.fr tionary arms race, where the two partners are continuously selected to avoid the cost of infection and the cost of immune clearance.

Cost of infection defines what is commonly called parasite virulence. Understanding and predicting the evolution of parasite virulence has been one of the major challenges for evolutionary biologists in the last decades [6]. It is striking that parasites do not exert similar amount of damage to their hosts. Some parasites can persist for years in a latent form with little or no cost for the host; others produce extensive damage that can result in a rapid host death. Why is there this variability? What are the selection pressures that drive the evolution of virulence towards lethal or benign variants?

Recent theory on the evolution of virulence has been built on the following background [7]. Parasite fitness clearly depends on its ability to spread the infection among hosts. Between-host transmission is likely to be positively linked to the amount of propagules produced, or in other terms to parasite multiplication rate. A parasite that reproduces rapidly, at a high rate, has a higher chance to be successfully transmitted than a parasite that multiplies slowly, at a low rate. Nevertheless, parasite multiplication is supposed to induce damage to the host. Rapidly multiplying parasites are those that risk killing the host. Host death stops the duration of the infection and parasite transmission. Parasite reproduction, therefore, increases parasite transmission and, as such, parasite fitness, but also increases the risk of host death setting a limit to the fitness rewards. Depending on the strength of the selection acting up and downwards, parasites can evolve towards increased or decreased levels of virulence.

According to this scenario, virulence is the direct consequence of energy/resource spoliation due to parasite multiplication. Now, in many host-parasite interactions there is no simple relationship between parasite density (the number of parasite individuals within the host) and the cost of the infection [8]. One of the reasons for this mismatch is due to the 
damage caused by the host immune response itself. As mentioned above, the first line of immune defences relies on a number of non specific effectors that in addition to the structures of the invading pathogen also produce damage to the host structures. Pro-inflammatory cytokines produced during an infectious process can result in extensive host damage [9]. The severity of many infectious diseases is, indeed, more the consequence of an over reacting immune response rather then parasite multiplication per se, especially when the intensity of the immune response is not a linear function of parasite density. In this case, the definition of parasite virulence needs to be extended as to include the immunopathology cost [10].

Parasite virulence is a composite trait that depends both on the strategy of host exploitation (a parasite trait) as well as on the regulation of the immune response (a host trait). Predicting the evolutionary trajectory of virulence, therefore, requires disentangling the relative contribution of these two traits to host mortality.

The interaction between the host immune response and the parasitic strategy of host exploitation takes place in an environment that is variable both in space and time [11]. Environmental condition is, therefore, an additional, important source of variation that shapes the benefits of host resistance and the cost of infection. There is now accumulating evidence showing that a number of environmental factors (food availability, stress, etc.) can largely affect the outcome of the interaction between hosts and parasites and as such contribute to the forces driving the evolution of resistant hosts and virulent parasites.

Birds have been the object of extensive study with respect to the coevolutionary interactions with pathogens [1214]. Wild, free-ranging, bird species have been studied as model organisms to forecast the ecological impact of infectious diseases; pathogens of domestic birds have been extensively studied because of the economic impact they can have on the poultry industry. Recently, the study of avian pathogens has regained considerable attention also because of the risk of bird to human pathogen transmission [15].

In this article, we discuss some of the aspects linked to the evolution of virulence and host immunity in bird-parasite systems. Although most of the best described mechanisms of pathogenesis involve poultry parasites, we will take care to cover some of the examples dealing with wildlife species.

\section{COSTS OF INFECTION}

Birds harbour a large spectrum of parasite species including all the major parasitic taxa [14]. The cost of infection is extremely variable among these parasitic species. Some pathogens have become textbook examples of the potential impact of the infection on host fitness and the persistence of infected host populations. Particular attention has been devoted to the cases where parasites have reached novel, immunologically naive, hosts either naturally or as the result of human activities.

\section{Avian Malaria and the Epidemics of Hawaiian Passerines}

Haemosporidia are common blood parasites infecting a wide diversity of bird hosts across different continents [16]. Three genera belong to this group of parasites: Plasmodium,
Haemoproteus and Leucocytozoon. Plasmodium parasites have been the object of recent research both in wildlife and domestic birds [17-22]. The cost of infection is quite variable and likely to depend on a number of factors. Host age, for instance, is a major determinant of the outcome of the infection of chickens with Plasmodium gallinaceum, with mortality ranging from $80 \%$ to $10 \%$ depending on the age of the host (from 7 to 84 days) [20]. Although not fully explored, the reason for this age-dependent cost of infection is likely due to the lack of protective immunity in young birds.

Assessing the cost of malaria infection in wild birds has been more challenging, because of the difficulty to experimentally manipulated parasite intensity. Recently, however, two approaches have been adopted to explore the impact of malaria infection on host fitness: experimental infections and antimalarial treatments. In both cases, the infection generates costs for the host in terms of physiology, and reproductive success [23-26].

To corroborate the idea that immunologically naive birds can pay a substantial cost when exposed to Plasmodium, the colonization of the Hawaiian archipelago by the parasite has produced a dramatic decline of native birds living at low altitudes [27]. Host populations located at mid-high altitude have suffered less from malaria, probably because the mosquito vector is rarer at high altitude. A remarkable series of experimental infection studies has provided quantitative estimates of the cost of infection suffered from low-elevation native birds both in terms of survival and reproductive success [17, 28-31].

Interestingly, low elevation populations of highly susceptible hosts have started to recover in number [32]. The reason for this is probably that, in spite of still high malaria prevalence, selection pressures exerted by the parasite have favoured hosts that can cope with the infection (contract the parasite but do not pay the extremely high cost observed during the first phase following the pathogen introduction). These results, therefore, convincingly show that parasiteexerted selection has promoted the decline and a subsequent spread of resistant/tolerant hosts within low elevation populations of Hawaiian birds [33]. We are now waiting for the next move: how parasites will adapt to the spread of resistant/tolerant hosts.

\section{The Epidemics of Mycoplasma gallisepticum in the House Finch}

The house finch (Carpodacus mexicanus) is a common passerine of North America. In 1994 an epidemic outbreak involving the house finch and the bacterium Mycoplasma gallisepticum was first recorded in a few localities of the East coast of the United States [34,35]. Since then the disease has progressed westwards with a substantial impact on the demography of the host populations, the size of the eastern house finch population having been reduced by a factor of two [36]. The disease induces a number of symptoms, the most visible being a swelling of the eyes (conjunctivitis). The infection reduces both the survival prospect and the reproductive success although the dynamics of the infection follows a seasonal pattern [36-38]. As for the avian malaria in the Hawaiian archipelago, the arrival of the epidemic wave at a given site has been rapidly followed by a decrease in the percentage of birds showing the symptoms of the dis- 
ease [39]. This has led to the hypothesis of selection for resistant hosts in the local populations. Indeed, the epidemics seem to have left a footprint on the genetic structure of immune genes of the host, although definitive evidence is still waiting [39].

These two text-book examples illustrate a few key, general, characteristics of bird-parasite interaction: 1) cost of infection is variable and depends on a number of host and parasite traits; 2) when parasites exert strong and constant selection pressures, the initial decrease in the host population size is generally followed by the spread of resistant/tolerant hosts; 3 ) the immune system (immune genes) seems to be one of the targets of parasite-exerted selection pressures.

\section{ENVIRONMENTAL EFFECTS MODULATING THE COST OF INFECTION}

As mentioned above, the outcome of the encounter between a host and a pathogen depends on numerous factors, including the host and pathogen genetic makeup as well as the environmental conditions where the interaction takes place [40]. Each of these factors has been shown to be variable: hosts differ in a number of genes involved in parasite resistance (see for instance the hyper-variable MHC genes) [41-43]; pathogens differ in genes responsible for infectivity and immune evasion [44,45]; finally, environmental conditions are seldom constant in time and space. Taking into account this variability is of prime importance for our understanding of the ecology of host-parasite interactions [46].

Studies that have addressed the interaction between host and parasite genotypes using birds (and in general vertebrates) are understandably rare. This approach has been mostly adopted for hosts with asexual reproduction where clones can be easily infected with different parasite strains [47].

One of the rare studies, dealing with a bird species, addressing the importance of genetic variation among hosts and parasite strains for the outcome of the interaction has been recently published by Hõrak et al. [48]. They experimentally infected greenfinches (Carduelis chloris) with single and multiple coccidian strains (Isospora lacazei). Although they did not directly assess the genetic variation of hosts and parasites, this experimental design allowed them to show that greenfinches with low pre-experimental intensity still suffered from a low intensity upon re-infection with multiple strains. This suggests that hosts were consistently able to cope with the infection and might reflect an underlying genetic variation, especially because they did not find a protective immunity when birds were infected twice with the same parasite strain. Comparing the virulence between single and multiple strain infections, they also showed that the multiple strain infection produced higher costs for the host. This, therefore, suggests that multiple infections potentially contain parasite strains with genetically variable propensity to harm the host.

Certainly, birds are more amenable to the study of the environmental modulation of the cost of infection. The environment, here, refers to all the interactions an organism has with the surrounding biotic and abiotic factors. These, obviously, include the amount of available trophic resources, the interactions with conspecific individuals or heterospecific competitors, or any other stressful condition.

The availability of certain food types is of prime importance for the outcome of the interaction between hosts and parasites, especially for those parasites with complex life cycles. The acanthocephalan Polymorphus phippsi exploits two hosts: an intermediate amphipod host and a final bird host. Steller's eiders (Polysticta stelleri) can feed on infected gammarids and get the infection. Bustnes and Glaktionov [49] have recently shown, in Northern Norway, that the likelihood to feed on gammarids depends on the body condition of birds. Birds in prime body condition tend to feed more on isopods whereas juvenile birds in poor body condition tend to prefer amphipods. Isopods are a rarer resource but they do not carry the acanthacephalan. Because of the lower abundance of isopods, birds in poor body condition probably cannot afford to pay the cost of selectivity [49]. This example illustrates one possible complex interaction between environmental condition and individual behaviour in the likelihood to contract the infection.

Food composition is also important because this is one of the well known environmental factors affecting immune responsiveness and potentially parasite resistance [50]. In an experimental set up, Gonzalez et al. [51] manipulated the amount of protein available in the diet of captive house sparrows (Passer domesticus). They found that sparrows provided with a high protein diet mounted a stronger immune response to a mitogen. Interestingly, these birds were also those with the highest recovery rate from a natural infection with avian malaria and with the best survival prospect.

The outcome of the interaction between hosts and parasites is also very sensitive to environmental stresses [52]. Organisms respond to stress with a series of physiological changes, mostly mediated by hormonal effectors. These hormones, especially corticosterone, have pleiotropic effects on different aspects of the energetic balance and are known to impact the functioning of the immune response [52]. Life is punctuated by stressful events. Rapid growth, breeding, moult, migration are all periods of intense stress for birds, likely to alter the protective ability of the immune response and facilitate the relapse of infectious diseases. To explore this issue, Gylfe et al. [53] conducted an elegant experiment. They experimentally infected juvenile redwing thrushes (Turdus iliacus) with an isolate of the spirochete bacterium Borrelia garinii (the agent of the Lyme disease). The birds were subsequently divided into two groups: one group experienced progressively shortening day length (mimicking the reduced day-length of fall), the other group experienced constant day length. The reduction in day length stimulates the migratory behaviour in many migratory birds and increases the nocturnal activity (a behaviour called migratory restlessness). This increased nocturnal activity produced a remarkable effect on the relapse of Borrelia infection. Whereas infection was not detectable from samples collected up to day 71 post infection, the proportion of positive samples increased to $62 \%$ in the migratory group during the restlessness period (Fig. 1).

\section{THE COST OF IMMUNITY}

The severity of an infectious disease depends on number of factors. Parasites that replicate within a host consume re- 


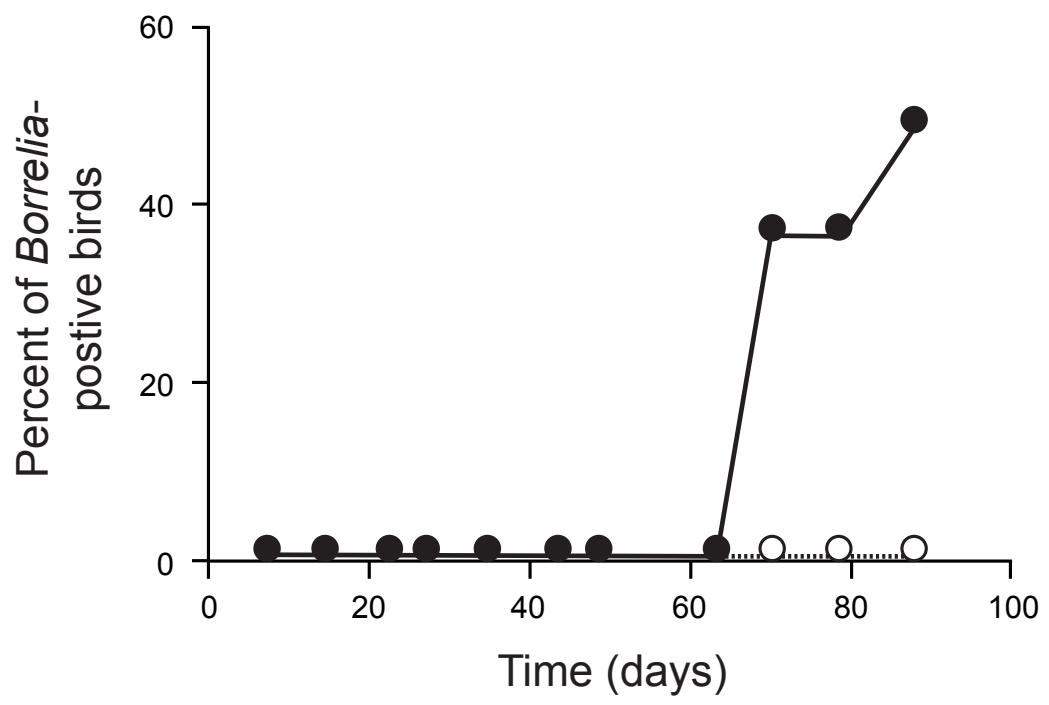

Fig. (1). Reactivation of infection with Borrelia garinii in redwing thrushes. Birds experimentally stimulated to engage in migratory behaviour are represented by the solid line and filled dots. The control, non migratory, group of birds is represented by the dashed line and open dots. (Modified from [53]).

sources that are no longer available for host growth, reproduction and survival. There is, therefore, a direct spoliation effect of the infection. In addition to this, upon entering the host an invading parasite activates and stimulates the host immune response. This activation is obviously an adaptive host response that should protect it against the parasite [4]. However, the immune response can also generate a cost. First, immune functioning is energetically costly [54]; second, a misdirected or over-reacting immune response can damage host structures (cells and tissues) [55]. The cost of infection, therefore, is the result of the additive effects of direct parasite spoliation and the cost of immunity.

Cost of immunity has attracted considerable attention especially in the ornithologist community. This is because assessing the cost of immune functioning has proven to be more feasible than directly assessing the cost of resistance towards a given pathogen. Performing controlled experimental infections is challenging in many natural systems and may raise important ethical issues. An alternative has been to assess the cost of mounting an immune response using challenges with antigenic compounds that are readily cleared by the organism and are supposed to induce a mild distress.

The immune system is an energetically demanding function. The energetic cost of immune activation has been measured in a few bird species with mixed results [56-60]. The general protocol consists in injecting an antigenic stimulus and measuring the basal metabolic rate of challenged and control birds. Although the majority of the published studies seem to confirm that mounting an immune response requires additional resources, the magnitude of the cost appears to be quite variable and, more importantly, one might wonder how this energetic cost translates in terms of fitness.

To address this issue, the focus has been put on the life history consequences of immune activation. Here, instead of measuring the metabolic rate at rest in the lab, free-ranging birds have been exposed to an immune insult during some of the key life-history periods (during growth or breeding) and the consequences of the challenge assessed in comparison to a control, non challenged, group. In most cases, again, the results concord to show that immune activation is paid in terms of reduced growth, reduced reproductive output or even increased probability of mortality [61-66].

In addition to the energetic cost of mounting an immune response, a misdirected or an over-reacting immune response can produce substantial, in some cases lethal, effects on the host [55]. Many immune effectors trigger non specific (inflammatory) responses that can target the pathogen as well as the host structures [9]. In addition, shared epitopes between the pathogen and the host can elicit specific responses against the host. Finally, auto-reactive lymphocytes bypassing the selection operated in the thymus can produce devastating effect on the host.

What is the evidence in support of the immunopathology cost in avian models? Assessing the immunopathology, independently of other energetic costs, requires a series of immunological tools that are rarely available for non model species. Most of the evidence, therefore, comes from infectious diseases of poultry.

The infectious bursal disease virus (IBDV) is an important poultry pathogen that induces variable mortality rate upon infection. The pathogenesis of the virus seems to be related to the activation of specific immune effectors. Although different strains of IBDV can have similar replication rate in the site of infection, they can differ in the stimulation of cellular immune response and subsequent production of nitrite. This strong systemic reaction, involving macrophages, is thought to produce the lesions induced by the infection [67].

The haemorrhagic enteritis virus is another major viral disease of domestic birds (turkeys), the economic impact of the disease having been estimated at more than 3 million dollars during the pre-vaccine era. The pathogenesis is thought to be the result of massive release of proinflammatory cytokines inducing a haemorrhagic shock in the intestine of infected birds [68]. 
In a more ecological context, recently it has been argued that the activation of the immune response, in particular the innate inflammatory response, can produce costs in terms of increased susceptibility to oxidative stress. Red blood cells of zebra finches whose immune response has been activated by an injection with bacterial lipopolysaccharid (a proinflammatory antigen) showed a reduction in their ability to sustain a controlled free-radical attack, suggesting an increased susceptibility to oxidation (Fig. 2, [69]). A recent metaanalysis has confirmed that this effect seems to extent to a larger number of bird species [70].

To conclude, there is now a large consensus to accept the idea that immunity is costly and that the currency in which the host pays this cost can take different forms. Importantly, however, whatever the currency of the cost (immunopathology or energy-based), immunity trades against life history traits.

\section{HOST IMMUNITY AND THE EVOLUTION OF VIRULENCE}

At the end of this article, it should be clear that the cost of infection, or in other words what is commonly called parasite virulence, depends both on the exploitation strategy of the parasite, and the cost of the immune response. Now, these two components of parasite virulence should probably not be seen as two independent traits. The host immune response can select more exploitative parasite strains and vice versa highly exploitative parasites can elicit stronger immune responses. A series of theoretical models have investigated the impact of host immunity on the evolution of parasite virulence [71-75]. Rarer have been the experimental studies that have tested the predictions put forward by this theoretical work [76].

A particular form of host immunity is vaccination. The rationale of vaccination rests on the memory properties of the immune response. Upon encounter with a specific pathogen epitope, the immune response builds up a class of mem- ory cells that provide a rapid and effective response upon reexposure with the same epitope. Depending on the nature of the vaccine, however, the protective effect can take different forms [72]. The vaccine can, for instance, stop parasite transmission, or it can reduce parasite multiplication (reducing therefore the symptoms of the disease) without completely stopping the transmission of the pathogen, finally the vaccine can target the toxins produced by the pathogen which in some cases are the causative agents of the disease symptoms. Recent theoretical models have shown that, depending on the type, vaccines can select for pathogens with increased damage on the host (increased virulence) [72,77]. This is because vaccines that do not stop parasite transmission but protect the host from the parasite-induced mortality, weaken the selection pressures acting against virulence. This is a particularly worrisome prediction because of the extensive use of vaccination in humans and domestic animals.

Empirical support to the idea that vaccination can drive the evolution of parasite virulence comes from a well known avian pathogen. Marek's disease virus has been a threat for the poultry industry for decades [78]. The disease is due to an oncogenic herpesvirus that produces a series of symptoms including leg paralysis, tumours in visceral organs, and finally the death of the host. The XIXth century has witnessed the emergence of viral strains with increased pathogenic profile. Interestingly, the emergence of such increasingly virulent strains coincides with a number of human-driven events. First, the shift in the rearing methods from a rural to an industrial-based, intensive, poultry production; second, the vaccination program [79]. Three successive vaccination programmes have been associated with the subsequent emergence of viral strains with increased virulence (Fig. 3). These results, therefore, strongly suggest that host immunity does affect the evolution of parasite virulence in bird - parasite associations. Although highly suggestive, these correlative results need to be confirmed by experimental studies where, for instance, parasites are serially passaged among immunocompetent, immunosuppressed and control hosts. The results

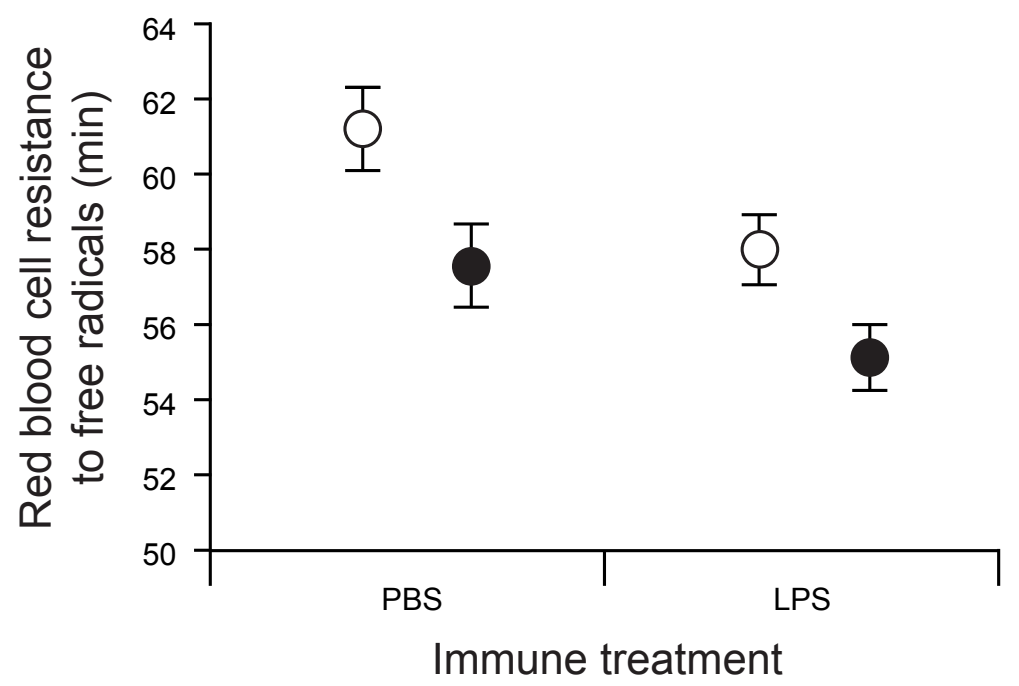

Fig. (2). Effect of the activation of the inflammatory response on the ability of zebra finch red blood cells to withstand a controlled freeradical attack. PBS = Phosphate buffer saline; LPS = Escherichia coli lipopolysaccharid; Open circles = males; Filled circles $=$ females. Bars represent standard errors. (Modified from [69]). 


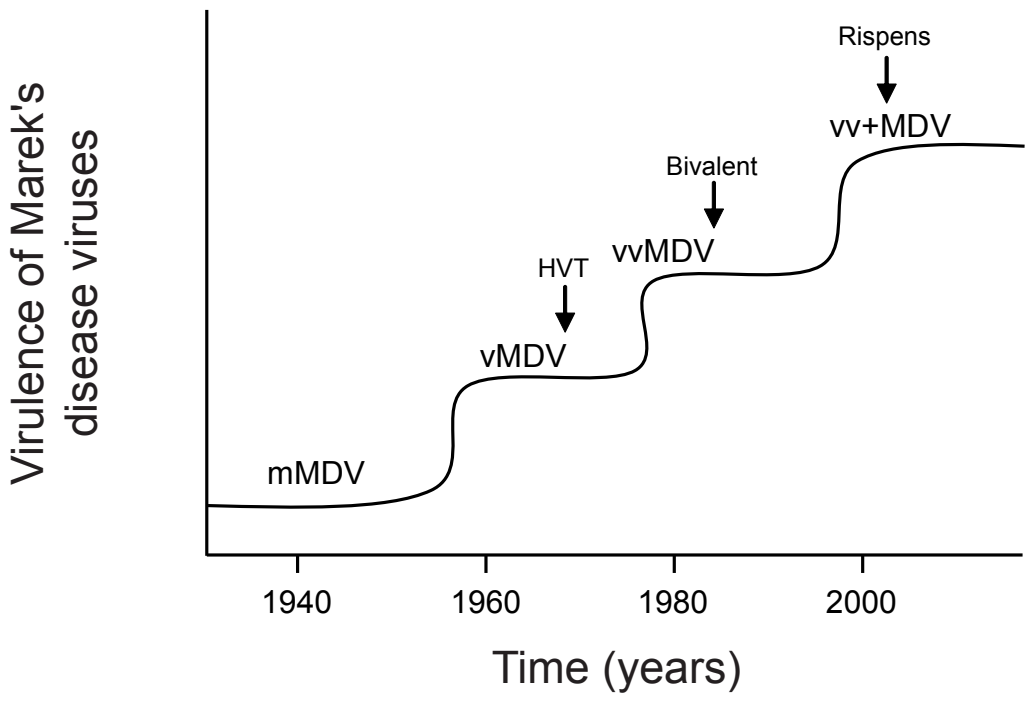

Fig. (3). The emergence of increasingly virulent Marek's disease viruses in the last decades. mMDV, vMDV, vvMDV and vv+MDV refer to the different strains (mild, virulent, very virulent and very virulent + ) that have emerged. HTV, bivalent, and Rispens refer to the different vaccines that have been used to protect poultry from the disease. The vertical arrows indicate the start of the different vaccination programmes. (Modified from [79]).

of these experimental evolution studies will certainly provide us with a much better picture on the interplay between host immunity and parasite virulence.

\section{CONCLUSION}

Hosts and parasites are involved in an endless arms race where hosts aim at avoiding the cost inflicted by the parasite and the parasite to optimise host exploitation. The outcome of this interaction depends on host and parasite genetics as well as on the environment where the interaction takes place. For the host the environment includes, among other factors, the availability of trophic resources, the presence of stressors, any social interaction, etc. Interestingly, however, the most important environmental factor parasites have to cope with is the host itself and in particular the immune system. This sets the scene for a coevolutionary scenario between the host immune response and the strategies of exploitation deployed by the parasites. We have seen that birds are very useful systems to address these questions. There is now an ample literature showing that the immune response incurs costs to the host, indicating that maximal defence is not synonymous of optimal defence. Other aspects of the interaction between hosts and pathogens have been less explored. we have identified two areas of research where more experimental work would be more than welcome. First, although we know that environmental conditions affect the expression of host immune response, the link between immune response and actual parasite resistance is not so obvious. It would be very interesting to explore more how the environment, in all its major facets, affects the cost of the infection. Similarly, we need to know if the impact of the environment on the cost of the infection is due to a differential cost of immunity or to increased/decreased host exploitation. It is probably difficult to run this kind of experiments using free-ranging birds. However, some model species are now routinely studied in captivity. These species might prove very useful to explore these questions. The second area of research that definitely requires additional work is the evolution of parasite viru- lence in response to host immunity. This is almost a virgin area of research, whatever the host-parasite association considered. Because of the facility to maintain some bird species in captivity, they are again very good candidates to explore this fascinating aspect of host-parasite co-evolution.

\section{ACKNOWLEDGEMENTS}

This work has been supported by the Agence Nationale de la Recherche (ANR), the Région Bourgogne and the CNRS (program MIE).

\section{REFERENCES}

[1] Thompson JN. Variation in interspecific interactions. Annu Rev Ecol Syst 1988; 19: 65-87.

[2] Chesson P. Mechanisms of maintenance of species diversity. Annu Rev Ecol Syst 2000; 31: 343-66.

[3] Combes C. Parasitism. the ecology and evolution of intimate interactions. Chicago: Chicago University Press 2001.

[4] Kaufmann SHE, Sher A, Ahmed R. Immunology of infectious diseases. Washington DC: ASM Press 2002.

[5] Schmid-Hempel P. Parasite immune evasion: a momentous molecular war. Trends Ecol Evol 2008; 23: 318-26.

[6] Dieckmann U, Metz JAJ, Sabelis MW, Sigmund K. Adaptive dynamics of infectious diseases: in pursuit of virulence management. Cambridge studies in adaptive dynamics. Cambridge: Cambridge University Press 2002.

[7] Alizon SA, Hurford A, Mideo N, van Baalen M. Virulence evolution and the trade-off hypothesis: history, current state of affairs and the future. J Evol Biol 2009; 22: 245-59.

[8] Graham AL, Allen JE, Read AF. Evolutionary causes and consequences of immunopathology. Annu Rev Ecol Evol Syst 2005; 36 373-97.

[9] Sorci G, Faivre B. Inflammation and oxidative stress in vertebrate host-parasite systems. Philos Trans R Soc B 2009; 364: 71-83.

[10] Day T, Graham AL, Read AF. Evolution of parasite virulence when host responses cause disease. Proc R Soc B 2007; 274: 268592.

[11] Lazzaro BP, Little TJ. Immunity in a variable world. Philos Trans R Soc B 2009; 364: 15-26.

[12] Loye JE, Zuk M. Bird-Parasite interactions. Oxford: Oxford University Press 1991.

[13] Clayton DH, Moore J. Host-parasite evolution. General principles and avian models. Oxford: Oxford University Press 1997. 
[14] Atkinson CT, Thomas NJ, Hunter DB. Parasitic diseases of wild birds. Australia: Wiley Blackwell 2008.

[15] Li KS, Guan Y, Wang J, et al. Genesis of a highly pathogenic and potentially pandemic H5N1 influenza virus in Eastern Asia. Nature 2004; 430: 209-13.

[16] Valkiunas GN. Avian malaria parasites and other haemosporidia. USA: CRC Press 2005.

[17] Atkinson CT, Dusek RJ, Woods KL, Iko WM. Pathogenicity of avian malaria in experimentally-infected Hawaii amakihi. J Wildlife Dis 2000; 36: 197-204.

[18] Sol D, Jovani R, Torres J. Parasite mediated mortality and host immune response explain age-related differences in blood parasitism in birds. Oecologia 2003; 135: 542-7.

[19] Paulman A, McAllister MM. Plasmodium gallinaceum: Clinical progression, recovery, and resistance to disease in chickens infected via mosquito bite. Am J Trop Med Hyg 2005; 73: 1104-7.

[20] Williams RB. Avian malaria: clinical and chemical pathology of Plasmodium gallinaceum in the domesticated fowl Gallus gallus. Avian Pathol 2005; 34: 29-47.

[21] Bensch S, Waldenstrom J, Jonzen N, et al. Temporal dynamics and diversity of avian malaria parasites in a single host species. J Anim Ecol 2007; 76: 112-22.

[22] Loiseau C, Zoorob R, Garnier S, et al. Antagonistic effects of a Mhc class I allele on malaria-infected house sparrows. Ecol Lett 2008; 11: 258-65.

[23] Merino S, Moreno J, Sanz JJ, Arriero E. Are avian blood parasites pathogenic in the wild? a medication experiment in blue tits (Parus caeruleus). Proc R Soc Lond B 2000; 267: 2507-10.

[24] Marzal A, de Lope F, Navarro C, Møller AP. Malarial parasites decrease reproductive success: an experimental study in a passerine bird. Oecologia 2005;142: 541-5.

[25] Tomas G, Merino S, Moreno J, Morales J, Martinez-de la Puente J. Impact of blood parasites on immunoglobulin level and parental effort: a medication field experiment on a wild passerine. Funct Ecol 2007; 21: 125-33

[26] Palinauskas V, Valkiunas GN, Bolshakov CV, Bensch S. Plasmodium relictum (lineage $\mathrm{P}-\mathrm{SGS} 1$ ): Effects on experimentally infected passerine birds. Exp Parasitol 2008; 120: 372-80.

[27] van Riper CI, van Riper SG, Goff ML, Laird M. The epizootiology and ecological significance of malaria in Hwaiian (USA) land birds. Ecol Monogr 1986; 56: 327-54.

[28] Atkinson CT, Woods KL, Dusek RJ, Sileo LS, Iko WM. Wildlife disease and conservation in Hawaii: pathogenicity of avian malaria (Plasmodium relictum) in experimentally infected Iiwi (Vestiaria coccinea). Parasitology 1995; 111: S59-69.

[29] Yorinks N, Atkinson CT. Effects of malaria on activity budgets of experimentally infected juvenile apapane (Himatione sanguinea). Auk 2000; 117: 731-8.

[30] Atkinson CT, Lease JK, Drake BM, Shema NP. Pathogenicity, serological responses, and diagnosis of experimental and natural malarial infections in native Hawaiian thrushes. Condor 2001; 103 : 209-18.

[31] Kilpatrick AM, LaPointe DA, Atkinson CT, et al. Effects of chronic avian malaria (Plasmodium relictum) infection on reproductive success of Hawaii Amakihi (Hemignathus virens). Auk 2006; 123: 764-74.

[32] Woodworth BL, Atkinson CT, LaPointe DA, et al. Host population persistence in the face of introduced vector-borne diseases: Hawaii amakihi and avian malaria. Proc Natl Acad Sci USA 2005; 102: 1531-6.

[33] Foster JT, Woodworth BL, Eggert LE, et al. Genetic structure and evolved malaria resistance in Hawaiian honeycreepers. Mol Ecol 2007; 16: 4738-46.

[34] Fischer JR, Stallknecht DE, Luttrell MP, Dhondt AA, Converse KA. Mycoplasmal conjunctivitis in wild songbirds: the spread of a new contagious disease in a mobile host population. Emerg Infect Dis 1997; 3: 69-72.

[35] Dhondt AA, Tessaglia DL, Slothower RL. Epidemic mycoplasmal conjunctivitis in house finches from eastern north America. J Wildlife Dis 1998; 34: 265-80.

[36] Hochachka WM, Dhondt AA. Density-dependent decline of host abundance resulting from a new infectious disease. Proc Natl Acad Sci USA 2000; 97: 5303-6.

[37] Altizer S, Hochachka WM, Dhondt AA. Seasonal dynamics of mycoplasmal conjunctivitis in eastern north American house finches. J Anim Ecol 2004; 73: 309-22.
[38] Nolan PM, Roberts SR, Hill GE. Effects of Mycoplasma gallisepticum on reproductive success in house finches. Avian Dis 2004; 48: 879-85.

[39] Hess CM, Wang ZS, Edwards SV. Evolutionary genetics of Carpodacus mexicanus, a recently colonized host of a bacterial pathogen, Mycoplasma gallisepticum. Genetica 2007; 129: 217-25.

[40] Sorci G, Møller AP, Boulinier T. Genetics of host-parasite interactions. Trends Ecol Evol 1997; 12: 196-200.

[41] Ekblom R, Saether SA, Jacobsson P, et al. Spatial pattern of MHC class II variation in the great snipe (Gallinago media). Mol Ecol 2007; 16: 1439-51.

[42] Alcaide M, Edwards SV, Negro JJ, Serrano D, Tella JL. Extensive polymorphism and geographical variation at a positively selected MHC class IIB gene of the lesser kestrel (Falco naumanni). Mol Ecol 2008; 17: 2652-65

[43] Loiseau C, Richard M, Garnier S, et al. Diversifying selection on MHC class I in the house sparrow (Passer domesticus). Mol Ecol 2009; 18: 1331-40.

[44] Finlay BB, McFadden G. Anti-immunology: evasion of the host immune system by bacterial and viral pathogens. Cell 2006; 124 : 767-82.

[45] Brault AC, Huang CYH, Langevin SA, et al. A single positively selected west Nile viral mutation confers increased virogenesis in American crows. Nat Genet 2007; 39: 1162-6.

[46] Thompson JN. The geographic mosaic of coevolution. USA: The University of Chicago Press 2005

[47] Carius HJ, Little TJ, Ebert D. Genetic variation in a host-parasite association: potential for coevolution and frequency-dependent selection. Evolution 2001; 55: 1136-45.

[48] Hõrak P, Saks L, Karu U, Ots I. Host resistance and parasite virulence in greenfinch coccidiosis. J Evol Biol 2006; 19: 277-88

[49] Bustnes JO, Galaktionov KV. Evidence of a state-dependent tradeoff between energy intake and parasite avoidance in Steller's eiders. Can J Zool 2004; 82: 1566-71.

[50] Klasing KC. Nutritional modulation of resistance to infectious diseases. Poultry Sci 1998; 77: 1119-25.

[51] Gonzalez G, Sorci G, Møller AP, et al. Immunocompetence and condition-dependent sexual advertisement in male house sparrows (Passer domesticus). J Anim Ecol 1999; 68: 1225-34.

[52] Apanius V. Stress and immune defense. Adv Study Behav 1998; 27: 133-53.

[53] Gylfe A, Bergstrom S, Lunstrom J, Olsen B. Epidemiology reactivation of Borrelia infection in birds. Nature 2000; 403: 724-5.

[54] Demas GE, Chefer V, Talan MI, Nelson RJ. Metabolic costs of mounting an antigenstimulated immune response in adult and aged C57BL/6J mice. Am J Physiol 1997; 273: R1631-R37.

[55] Sell S. Immunology, immunopathology and immunity. $6^{\text {th }}$ ed. Washington: ASM Press 2001

[56] Ots I, Kerimov AB, Ivankina E, Ilyina TA, Hõrak P. Immune challenge affects basal metabolic activity in wintering great tits. Proc $\mathrm{R}$ Soc Lond B 2001; 268: 1175-81.

[57] Martin LB, Scheuerlein A, Wikelski M. Immune activity elevates energy expenditure of house sparrows: a link between direct and indirect costs? Proc R Soc Lond B 2003; 270: 153-8.

[58] Eraud C, Duriez O, Chastel O, Faivre B. The energetic cost of humoral immunity in the collared dove, Streptopelia decaocto: is the magnitude sufficient to force energybased trade-offs? Funct Ecol 2005; 19: 110-18

[59] Amat JA, Aguilera E, Visser GH. Energetic and developmental costs of mounting an immune response in greenfinches (Carduelis chloris). Ecol Res 2007; 22: 282-7.

[60] Nilsson JA, Granbom M, Råberg L. Does the strength of an immune response reflect its energetic cost? J Avian Biol 2007; 38 488-94.

[61] Bonneaud C, Mazuc J, Guillermo G, et al. Assessing the cost of mounting an immune response. Am Nat 2003; 161: 367-79.

[62] Hanssen SA, Hasselquist D, Folstad I, Erikstad KE. Cost of immunity: immune responsiveness reduces survival in a vertebrate. Proc R Soc Lond B 2004; 271: 925-30.

[63] Ardia DR. Tree swallows trade off immune function and reproductive effort differently across their range. Ecology 2005; 86: 2040-6.

[64] Hanssen SA. Costs of an immune challenge and terminal investment in a long-lived bird. Ecology 2006; 87: 2440-6.

[65] Marzal A, Reviriego M, de Lope F, Møller AP. Fitness costs of an immune response in the house martin (Delichon urbica). Behav Ecol Sociobiol 2007; 61: 1573-80. 
[66] Eraud C, Jacquet A, Faivre B. Survival cost of an early immune soliciting in nature. Evolution 2009; 63: 1036-43.

[67] Rautenschlein S, Yeh HY, Sharma JM. Comparative immunopathogenesis of mild, intermediate, and virulent strains of classic infectious bursal disease virus. Avian Dis 2003; 47: 66-78.

[68] Rautenschlein S, Sharma JM. Immunopathogenesis of Haemorrhagic Enteritis Virus (HEV) in Turkeys. Dev Comp Immunol 2000; 24: 237-46.

[69] Bertrand S, Criscuolo F, Faivre B, Sorci G. Immune activation increases susceptibility to oxidative tissue damage in zebra finches. Funct Ecol 2006; 20: 1022-7.

[70] Costantini D, Møller AP. Does immune response cause oxidative stress in birds? a metaanalysis. Comp Biochem Physiol A 2009; 153: 339-44.

[71] Antia R, Levin BR, May RM. Within-host population-dynamics and the evolution and maintenance of microparasite virulence. Am Nat 1994; 144: 457-72.

[72] Gandon S, Mackinnon MJ, Nee S, Read AF. Imperfect vaccines and the evolution of pathogen virulence. Nature 2001; 414: 751-6.
[73] Andre JB, Ferdy JB, Godelle B. Within-host parasite dynamics, emerging trade-off, and evolution of virulence with immune system. Evolution 2003; 57:1489-97.

[74] Fenton A, Lello J, Bonsall MB. Pathogen responses to host immunity: the impact of time delays and memory on the evolution of virulence. Proc R Soc B 2006; 273: 2083-90.

[75] Alizon S, van Baalen M. Multiple infections, immune dynamics, and the evolution of virulence. Am Nat 2008; 172: E150-E68.

[76] Mackinnon MJ, Read AF. Immunity promotes virulence evolution in a malaria model. PLoS Biol 2004; 2: 1286-92.

[77] Gandon S, Mackinnon M, Nee S, Read A. Imperfect vaccination: some epidemiological and evolutionary consequences. Proc R Soc Lond B 2003; 270: 1129-36.

[78] Davison F, Nair V. Marek's disease. an evolving problem. USA Elsevier 2004.

[79] Nair V. Evolution of marek's disease: a paradigm for incessant race between the pathogen and the host. Vet J 2005; 170: 175-83.

(c) Sorci and Cornet; Licensee Bentham Open.

This is an open access article licensed under the terms of the Creative Commons Attribution Non-Commercial License (http://creativecommons.org/licenses/ by-nc/3.0/) which permits unrestricted, non-commercial use, distribution and reproduction in any medium, provided the work is properly cited. 